\title{
Open access intrapartum CTG database
}

\author{
Václav Chudáček ${ }^{1 *}$, Jiří Spilka ${ }^{1}$, Miroslav Burša ${ }^{1}$, Petr Jankư², Lukáš Hruban², Michal Huptych ${ }^{1}$ \\ and Lenka Lhotská ${ }^{1}$
}

\begin{abstract}
Background: Cardiotocography (CTG) is a monitoring of fetal heart rate and uterine contractions. Since 1960 it is routinely used by obstetricians to assess fetal well-being. Many attempts to introduce methods of automatic signal processing and evaluation have appeared during the last 20 years, however still no significant progress similar to that in the domain of adult heart rate variability, where open access databases are available (e.g. MIT-BIH), is visible. Based on a thorough review of the relevant publications, presented in this paper, the shortcomings of the current state are obvious. A lack of common ground for clinicians and technicians in the field hinders clinically usable progress. Our open access database of digital intrapartum cardiotocographic recordings aims to change that.

Description: The intrapartum CTG database consists in total of 552 intrapartum recordings, which were acquired between April 2010 and August 2012 at the obstetrics ward of the University Hospital in Brno, Czech Republic. All recordings were stored in electronic form in the OB TraceVue ${ }^{\oplus}$ system. The recordings were selected from 9164 intrapartum recordings with clinical as well as technical considerations in mind. All recordings are at most 90 minutes long and start a maximum of 90 minutes before delivery. The time relation of CTG to delivery is known as well as the length of the second stage of labor which does not exceed 30 minutes. The majority of recordings (all but 46 cesarean sections) is - on purpose - from vaginal deliveries. All recordings have available biochemical markers as well as some more general clinical features. Full description of the database and reasoning behind selection of the parameters is presented in the paper.

Conclusion: A new open-access CTG database is introduced which should give the research community common ground for comparison of results on reasonably large database. We anticipate that after reading the paper, the reader will understand the context of the field from clinical and technical perspectives which will enable him/her to use the database and also understand its limitations.
\end{abstract}

Keywords: Cardiotocography, Intrapartum, CTG, Database, Signal processing, Fetal heart rate

\section{Background}

\section{Introduction}

Fetal heart activity is the prominent source of information about fetal well being during delivery. Cardiotocography (CTG) - recording of fetal heart rate (FHR) and uterine contractions - enables obstetricians to detect fetus with deteriorating status (e.g. ongoing fetal hypoxia), which may occur even in a previously uncomplicated pregnancy. Even though fetus has its own natural defense mechanism to tackle the oxygen insufficiency during the delivery, in some cases only timely intervention can prevent adverse

\footnotetext{
${ }^{*}$ Correspondence: vaclav.chudacek@fel.cvut.cz

1 Department of Cybernetics, Faculty of Electrical Engineering, Czech

Technical University in Prague, Prague, Czech Republic

Full list of author information is available at the end of the article
}

consequences. Hypoxia, with prevalence lying in the region of $0.6 \%$ [1] to $3.5 \%$ [2], is considered to be the third most common cause of newborn death [3].

Cardiotocography was introduced in late 1960s and is still the most prevalent method of intrapartum hypoxia detection. It did not, however, bring the expected improvements in the delivery outcomes in comparison to previously used intermittent auscultation [4]. Moreover, continuous CTG is the main suspect for growing percentage of cesarean sections (CS) for objective reasons, which increased in the last decade [5].

To tackle the problems of CTG three principal approaches were followed during the years. The first approach focused on improving low inter and intra-observer agreement [6]. In 1986 International Federation of Gynecology and Obstetrics (FIGO) introduced general guidelines [7] 
based on evaluation of macroscopic morphological FHR features and their relation to the tocographic measurement. But even though the guidelines are available for almost thirty years now, poor interpretation of CTG still persists [8-10]. Many tweaks to the guidelines were proposed during the years, but with no significant change to the inter-observer variability. For overview of the different guidelines we refer the reader to [11].

The second approach to improve the overall results of CTG looks for technical solutions to add more objective/quantitative evaluation of the state of the fetus using additional measurement techniques. Some used techniques are regionally/country limited in their use - such as fetal blood sampling $[12,13]$ or fetal pulse oxymetry [14]. The only widespread method is evaluation of averaged repolarization behavior of fetal ECG performed by STAN. Many studies were published comparing STANenhanced CTG with use of CTG only. The majority of studies proved that the addition of STAN indeed leads to slightly better fetal outcomes $[15,16]$ but problems were also reported $[17,18]$.

Attempts to computer evaluation of the CTG - the third approach - started almost immediately after introduction of the first unified FIGO guidelines. FIGO features became fundamental in most of the first clinically oriented approaches and automatically extracted morphological features played the major role in all automatic systems for CTG analysis $[19,20]$.

We suggest interested reader to refer to e.g. [21] for more details on CTG preprocessing and to e.g. [22] for more details on different features that had been extracted to characterize the FHR since the focus of this paper is rather on the database presentation.

When reviewing literature on automatic CTG processing, two things are striking. First, there is a large disconnection between approaches and goals in the clinical and technical papers. The clinical papers are mostly looking for applicable solutions to the clinically pressing issues (lack of agreement, critically misclassified recordings). The technical papers often use CTG data as just an another input to the carefully tuned classifiers. Most works use very small ad-hoc acquired datasets, differently sampled with various parameters used as outcome measures, though we have to concede that our previous works $[22,23]$ were done exactly in the same manner. It is hard to believe that it is more than 30 years when computer processing of CTG has begun [24] and since then, no common database of CTG records is available ${ }^{\mathrm{a}}$. There is no way how to compare/improve/disregard among different results. And that, in our opinion, hinders any significant progress towards the ultimate goal of a usable and working automated classification of the CTG recordings.

In this paper we present a novel open-access CTG database, which we will call further in the paper CTU-
UHB database $\mathrm{e}^{\mathrm{b}}$. It consists of CTG records and clinical information. We first provide a comprehensive overview of databases used in literature in the last years. Then we describe development of the CTU-UHB database. We discuss the criteria for selection of records for the database from clinical and technical point of view. At last, we present a detailed description of main clinical and technical parameters, which, in our opinion, are important for understanding and should be taken into account when using the database.

\section{Overview of CTG databases used in literature}

We performed a systematic search in the electronic database PUBMED including records up to February 2013. The language of studies was restricted to English. The various combination of the following keywords were used: cardiotocography, fetal heart rate, fetal heart rate monitoring, computer assisted diagnosis, fetal distress, asphyxia, hypoxemia, fetal hypoxia. In the selected articles the references were searched and articles that cited the paper were searched as well.

It is impossible to provide exhaustive review and, therefore, several inclusion criteria were applied to include all relevant works but keep the overview as clear as possible. First, if a CTG database was used in multiple works, we included the paper where the database was described in most detail. If the description was the same, we included the most recent paper, e.g. we preferred paper of Jezewski et al. [25] rather than of Czabanski et al. [26]. Second, only those works that used intrapartum CTG signals were considered, e.g. we did not include the work of $\mathrm{H}$. Ocak [27] since he worked with UCI Cardiotocography Data Set ${ }^{\mathrm{c}}$. Third, we preferred journal papers and works that attempted to show results with regards to objective annotation $(\mathrm{pH}$, base excess, etc.).

Our search of CTG databases used in other studies (with applied selection criteria) resulted in inclusion of 22 works. Due to the space limitation the overview had to be split into two tables, Tables 1 and 2. Table 1 presents used databases regarding the CTG signals and clinical parameters, namely: type of acquisition (ultrasound Doppler (US), direct fetal electrocardiogram measurement (FECG)); antepartum (ante.) or intrapartum (inte.) phase; stage of labor (I. or II.); length of FHR signal; time to actual delivery; use of uterine contractions (UC), description of inclusion criteria; description of clinical data; evaluation type: objective (obj.), subjective (subj.), or combination of both (comb.); number of total cases. The number of cases varies from study to study, the lowest being around 50 cases, and the highest being 7568 cases. Table 2 presents the overview of databases from classification point of view. It is apparent that in each paper different criteria for classes division were used, thus, making any 
Table 1 Overview of databases used in various works I

\begin{tabular}{|c|c|c|c|c|c|c|c|c|c|c|}
\hline Reference & Acquisition & Timing & Labor stage & $\begin{array}{l}\text { FHR sig. used } \\
\text { [min] }\end{array}$ & $\begin{array}{l}\text { Time to delivery } \\
\text { [min] }\end{array}$ & UC used & $\begin{array}{l}\text { Incl. } \\
\text { criteria }\end{array}$ & $\begin{array}{l}\text { Clinical } \\
\text { info. }\end{array}$ & $\begin{array}{l}\text { Evaluation } \\
\text { type }\end{array}$ & $\begin{array}{l}\text { \# Total } \\
\text { cases }\end{array}$ \\
\hline Nielsen et al. 1988 [28] & N/A & intra. & I. & 30 & N/A & Yes & No & No & obj. & 50 \\
\hline Chung et al. 1995 [29] & FECG & intra. & N/A & N/A & N/A & Yes & Yes & Yes & obj. & 73 \\
\hline Keith et al. 1995 [30] & N/A & intra. & N/A & $>120$ & Until del. & Yes & No & Yes & comb. & 50 \\
\hline Bernardes et al. 1998 [31] & US, FECG & ante., intra. & I.,I. & - & Until del. & Yes & No & Yes & obj. & 85 \\
\hline Maeda et al. 1998 [32] & N/A & intra. & N/A & 50 & N/A & No & No & No & subj. & 49 \\
\hline Lee et al. 1999 [33] & FECG & intra. & N/A & - & N/A & Yes & No & No & subj. & 53 \\
\hline Chung et al. 2001 [34] & US & ante., intra. & I.,I. & N/A & 120 & No & No & Yes & comb. & 76 \\
\hline Strachan et al. 2001 [35] & FECG & intra. & ।.,I. & $>30$ & Until del. & Yes & No & Yes & obj. & 679 \\
\hline Siira et al. 2005 [36] & FECG & intra. & I.,I. & 60 & $95 \%$ bellow 9 & Yes & Yes & Yes & obj. & 334 \\
\hline Cao et al. 2006 [37] & US, FECG & intra. & N/A & 30 & N/A & Yes & No & No & subj. & 148 \\
\hline Salamalekis et al. 2006 [38] & US & intra. & I.,I. & N/A & Until del. & No & Yes & Yes & comb. & 74 \\
\hline Georgoulas et al. 2006 [39] & FECG & intra. & I.,I. & $20-60$ & Until del. & No & No & No & obj. & 80 \\
\hline Gonçalves et al. 2006 [40] & US, FECG & intra. & I.,I. & $32-60$ & Until del. & No & Yes & Yes & obj. & 68 \\
\hline Costa et al. 2009 [41] & FECG & intra. & I.,I. & - & Until del. & Yes & Yes & Yes & obj. & 148 \\
\hline Elliott et al. 2010 [42] & N/A & intra. & I.,Il. & $>180$ & Until del. & Yes & Yes & Yes & subj. & 2192 \\
\hline Warrick et al. 2010 [43] & US, FECG & intra. & I.,I. & $>180$ & Until del. & Yes & Yes & No & obj. & 213 \\
\hline Jezewski et al. 2010 [25] & US & ante., intra. & N/A & - & N/A & Yes & Yes & Yes & obj. & 749 \\
\hline Helgason et al. 2011 [44] & FECG & intra. & I.,I. & $>30$ & Until del. & Yes & No & No & comb. & 47 \\
\hline Chudacek et al. 2011 [22] & US, FECG & intra. & I.,I. & 20 & Until del. & No & Yes & Yes & comb. & 552 \\
\hline Spilka et al. 2012 [23] & US, FECG & intra. & I.,Il. & 20 & Until del. & No & Yes & No & obj. & 217 \\
\hline Georgieva et al. 2013 [45] & N/A & intra. & I.,I. & - & Until del. & No & Yes & Yes & obj. & 7568 \\
\hline Czabanski et al. 2013 [46] & N/A & ante., intra. & N/A & 60 & N/A & No & Yes & Yes & subj. & $2124^{\dagger}$ \\
\hline
\end{tabular}

Legend: "N/A" - information not available, " " " - authors used the whole available FHR signal without specifying the length, ${ }^{\dagger}-2124$ recordings, 333 woman 
Table 2 Overview of databases used in various works II

\begin{tabular}{|c|c|c|c|c|c|}
\hline Reference & Classes (categories) & $\begin{array}{l}\text { Division criteria for } \\
\text { classes }\end{array}$ & \# classes & \# cases in classes & \# total cases \\
\hline Nielsen et al. 1988 [28] & Normal; pathological & $\begin{array}{l}\text { Apgar } 1 \text { min. }<7 \text { or } p H< \\
7.15 \text { or } \mathrm{BE}<-10\end{array}$ & 2 & $34 ; 16$ & 50 \\
\hline Chung et al. 1995 [29] & Normal; abnormal & $\mathrm{pH}<7.15$ & 2 & $65 ; 8$ & 73 \\
\hline Keith et al. 1995 [30] & 5-tier scoring system & $\begin{array}{l}17 \text { clinicians, pH, BDecf, } \\
\text { Apgar }\end{array}$ & 5 & $38 ; 12$ & 50 \\
\hline Bernardes et al. 1998 [31] & norm.; susp.; pathol. & $\mathrm{pH}$, Apgar, neonatology & 3 & $56 ; 22 ; 7$ & 85 \\
\hline Maeda et al. 1998 [32] & norm.; susp.; pathol. & manual clinical rules & 3 & $12 ; 18 ; 19$ & 49 \\
\hline Lee et al. 1999 [33] & Normal CTG; decels. & 1 clinician & 2 & N/A & 53 \\
\hline Chung et al. 2001 [34] & $\begin{array}{l}\text { Normal; presumed } \\
\text { distress; acidemic }\end{array}$ & $\begin{array}{l}\text { norm. FHR; abnorm. \& } \\
\mathrm{pH}>7.15 \text {; abnorm. \& pH } \\
<7.15\end{array}$ & 3 & $36 ; 26 ; 14$ & 76 \\
\hline Strachan et al. 2001 [35] & Normal; abnormal & $\mathrm{pH} \leq 7.15 \&$ BDecf $>8$ & 2 & $608 ; 71$ & 679 \\
\hline Siira et al. 2005 [36] & Normal; acidemic & $\mathrm{pH}<7.05$ & 2 & $319 ; 15$ & 334 \\
\hline Cao et al. 2006 [37] & reassuring; NR & 2 clinicians & 2 & $102 ; 44$ & 148 \\
\hline Salamalekis et al. 2006 [38] & $\begin{array}{l}\text { Normal; NR [NR \& pH > } \\
7.20 ; \mathrm{NR} \& \mathrm{pH}<7.20]\end{array}$ & $\mathrm{FIGO}, \mathrm{pH}<7.20$ & 2 & $32 ; 42$ & 74 \\
\hline Georgoulas et al. 2006 [39] & Normal; at risk & $\mathrm{pH}>7.20 ; \mathrm{pH}<7.10$ & 2 & $20 ; 60$ & 80 \\
\hline Costa et al. 2009 [41] & $\begin{array}{l}\text { Omniview-SisPorto } \\
3.5 \text { alerts }\end{array}$ & $\mathrm{pH}<7.05$ & 2 & $7 ; 141$ & 148 \\
\hline Elliott et al. 2010 [42] & Normal; abnormal & $\mathrm{BDecf} \geq 12 \& \mathrm{NE}$ & 2 & $60 ; 2132$ & 2192 \\
\hline Warrick et al. 2010 [43] & Normal; pathological & BDecf $<8$; BDecf $\geq 12$ & 2 & $187 ; 26$ & 213 \\
\hline Jezewski et al. 2010 [25] & Normal; abnormal & $\begin{array}{l}\text { Apgar N/A min. }<7 \text { or } \\
\text { birth weight }<10^{\text {th }} \text { perc. } \\
\text { or } \mathrm{pH}<7.2\end{array}$ & 2 & $28 \%$ abnorm. & 749 \\
\hline Helgason et al. 2011 [44] & FIGO-TN; FIGO-FP; FIGO-TP & $\begin{array}{l}\text { norm. FHR \& pH } \geq 7.30 \\
\text { abnorm. \& } \mathrm{pH} \geq 7.30 \\
\text { abnorm. \& pH } \leq 7.05\end{array}$ & 3 & $15 ; 17 ; 15$ & 47 \\
\hline Chudacek et al. 2011 [22] & norm.; susp.; pathol. & 3 clinicians & 3 & $139 ; 306 ; 107$ & 552 \\
\hline Spilka et al. 2012 [23] & Normal; pathological & $\mathrm{pH}<7.15$ & 2 & $123 ; 94$ & 217 \\
\hline Georgieva et al. 2013 [45] & Normal; adverse & $\mathrm{pH}<7.1$ \& neonatology & 2 & N/A & 7568 \\
\hline Czabanski et al. 2013 [46] & Normal; abnormal & Apgar 10 min. $<5$ & 2 & $306 ; 27$ & $2124^{\dagger}$ \\
\hline
\end{tabular}

Abbreviations: NR - non-reassuring, NE - neonatal encephalopathy, ${ }^{\dagger}-2124$ recordings, 333 woman.

comparison of results between different studies virtually impossible.

\section{Construction and content \\ Ethics statement}

The CTG recordings and clinical data were matched by anonymized unique identifier generated by the hospital information system. The timings of CTG records were matched to stages of labor (first and second stage) and were made relative to the time of birth, thus also deidentified. This study was approved by the Institutional Review Board of University Hospital Brno; all women signed informed consent.

\section{Data collection}

The data were collected between $27^{\text {th }}$ of April 2010 and $6^{\text {th }}$ of August 2012 at the obstetrics ward of the University
Hospital in Brno (UHB), Czech Republic. The data consisted of two main components, the first were intrapartum CTG recordings and the second were clinical data.

The CTGs were recorded using STAN S21 and S31 (Neoventa Medical, Mölndal, Sweden) and Avalon FM40 and FM50 (Philips Healthcare, Andover, MA) fetal monitors. All CTG signals were stored in an electronic form in the OB TraceVue ${ }^{\circ}$ system (Philips) in a proprietary format and converted into text format using proprietary software provided by Philips. Each CTG record contains time information and signal of fetal heart rate and uterine contractions both sampled at $4 \mathrm{~Hz}$. When a signal was recorded using internal scalp electrode it also contained T/QRS ratio and information about biphasic T-wave. From 9164 intrapartum recordings the final database of 552 carefully selected CTGs was created keeping in consideration clinical as well as technical point of 
view; the details about recordings selection are provided further.

The clinical data were stored in the hospital information system (AMIS) in the relational database. Complete clinical information regarding delivery and fetal/maternal information were obtained. The clinical data included: delivery descriptors (presentation of fetus, type of delivery and length of the first and second stage), neonatal outcome (seizures, intubation, etc.), fetal and neonatal descriptors (sex, gestational week, weight, etc.), and information about mother and possible risk factors. For the final CTU-UHB database, clinical data were exported from relational database and converted into Physionet text format.

\section{Data selection and criteria considered}

The selection procedure of the records was based on both clinical and CTG signal parameters and the process is shown in Figure 1.

\section{Clinical criteria}

In the following paragraphs we describe criteria that were used for records exclusion. Additionally we discuss shortly the criteria that were included in the description of the final database but were not used for records exclusion.

Clinical selection criteria The following parameters were taken into account for inclusion of recordings into the final database. References in this section refer to a description of particular parameter.

- Women's Age - although the women's high age plays significant role in the probability of congenital diseases, for the intrapartum period no significance was found [47]. Low age (maternal age $<18$ years) could have an adverse effect [48] and such records were therefore excluded.

- Week of gestation - maturity of the fetus plays significant role in the shape and behavior of the FHR antepartum as well as intrapartum [49]. Therefore the selection was limited to mature fetuses (weeks of gestation $\geq 37$ ) according to the last menses counting, which was in majority cases confirmed by ultrasound measurement during antepartum check-ups.

- Known fetal diseases - fetuses with known congenital defects or known intrauterine growth restriction (IUGR) that could influence the FHR and/or outcome of the delivery were excluded from the database. Additionally, postnatally detected defects were consulted and two cases with transposed large veins were left in the set, since these two particular changes should not have influenced the FHR.

- Type of gravidity - only singleton, uncomplicated pregnancies were included.
- Type of delivery - the majority of the database consists of vaginal deliveries. Nevertheless to increase the number of cases with pathological outcome in the database, 16 CS recordings with $\mathrm{pH} \leq 7.05$ were included and consequently a control group consisting of 30 CS with normal outcomes was also included to enable separate evaluation if necessary.

Additional clinical criteria provided Together with criteria used for selection, the following criteria were considered and are available together with the CTG data:

- Sex of the fetus - both sexes were included even though the sex of fetus significantly influences the outcome according to Bernardes et al. [50].

- Parity - although the first delivery can be "more difficult" in general clinical sense [51] it is the same from the point of view of the FHR recording.

- Risk factors - to be able to describe and identify the a priori high-risk pregnancies. We have included risk factors that could have influenced the state of the baby before entering the labor. For full review of the parameters and further references we recommend paper of Badawi et al. [52]. The final risk factors included in the database were gestational diabetes, preeclampsia, maternal fever $\left(>37.5^{\circ} \mathrm{C}\right)$, hypertension and meconium stained fluid.

- Drugs - especially those administered during delivery were considered only with regard to their influence on FHR. Opiates may influence the FHR directly but are rarely used in the Czech Republic during delivery and were not used in any of the cases included in the database. Therefore, we do not provide information about drugs administration in the database. Note that e.g. oxytocin used for enhancement of the uterine activity influences the FHR in majority indirectly, via increase of uterine activity, and thus can be assessed from the CTG alone.

- Other criteria - complementary information in order to offer insight why e.g. operative delivery was chosen. These include: induced delivery, type of presentation (occipital/breech), no progress of labor, dystocia cephalocorporal (incoordinate uterine activity), dystocia cephalopelvic.

\section{Labor outcome measures}

Since our main intention was to prepare database that could be used for comparison of different automated approaches we have selected only those recordings that included umbilical artery $\mathrm{pH}$. We added all additional outcome measures that were available for the recording in the hospital information system. Some of these measures are often misused and we will discuss their disadvantages below. 

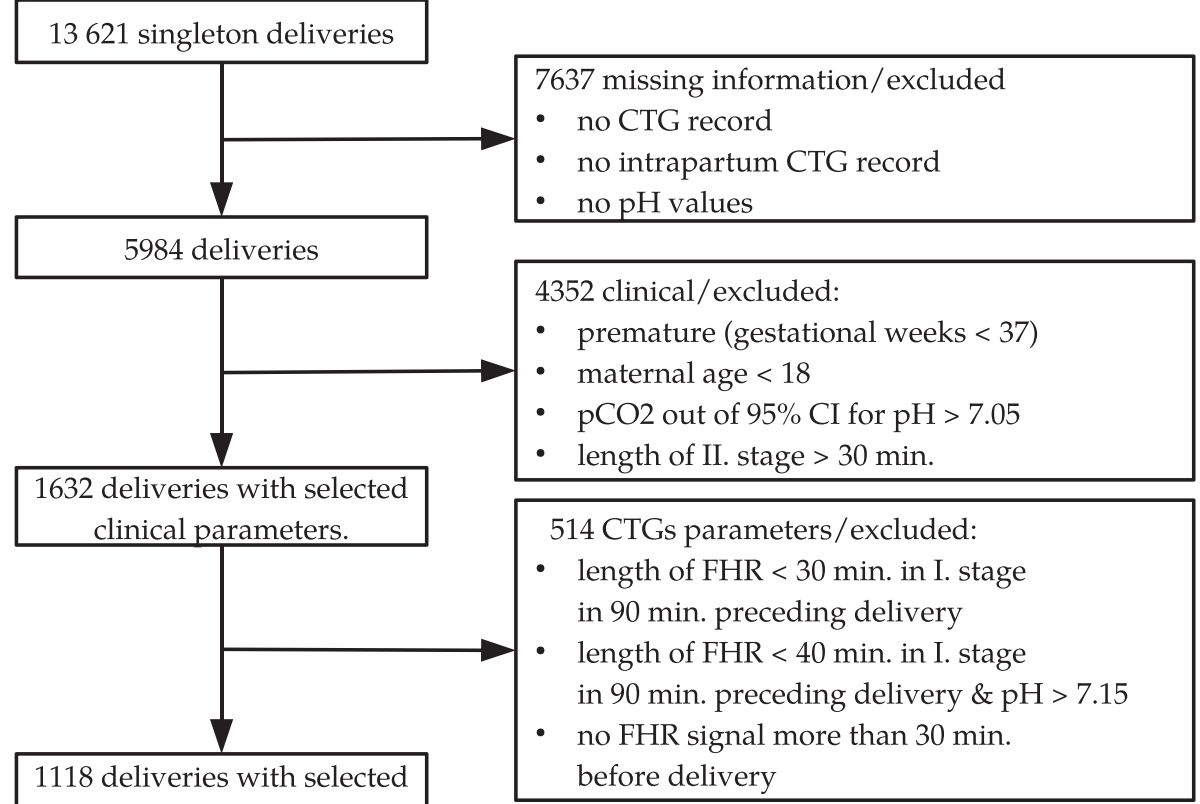

CTG parameters

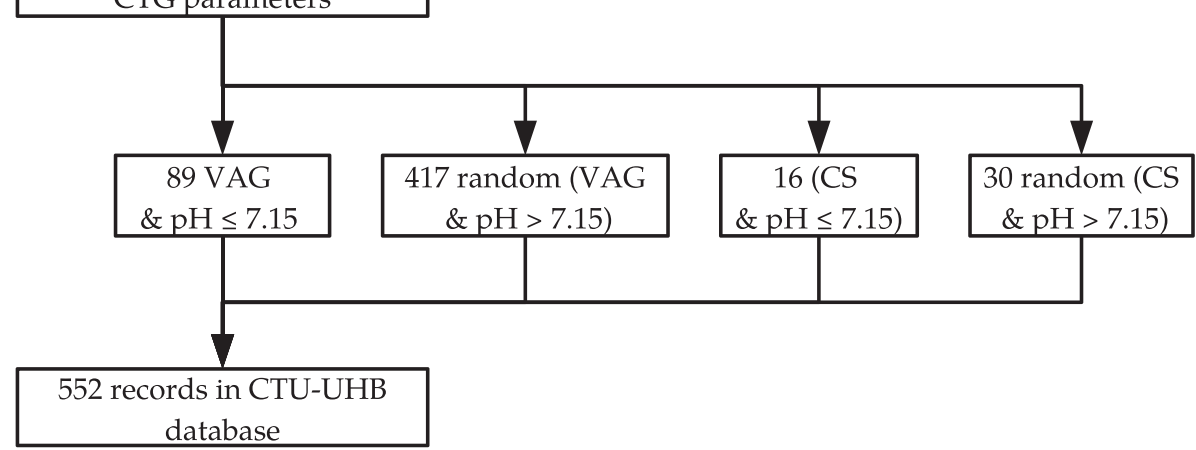

Figure 1 Selection of recordings for the final database. Flowchart diagram describing the process of data selection for the final database.

Outcome measure selection criteria To enable objective classification the $\mathrm{pH}$ measure was considered as essential for the evaluation of the database.

- Umbilical artery $\mathrm{pH}(\mathrm{pH})$ - is the most commonly used outcome measure, sign of respiratory hypoxia. Records with missing $\mathrm{pH}$ were excluded. Following suggestion by Rosen [53] records, which had values of $\mathrm{pCO}_{2}$ outside $95^{\text {th }}$ percentile [54] were excluded except those with $\mathrm{pH} \leq 7.05$, which even according to [54] should be approached with care.

Additional outcome measures provided Even though the is $\mathrm{pH}$ is the most commonly used measure, we included additional measures such as following:
- Base excess $(\mathrm{BE})$ - is often used in the clinical setting as a sign for metabolic hypoxia, but is often false positive [53].

- Base deficit in extracellular fluid (BDecf) - is according to Rosén et al. [53] a better measure of metabolic hypoxia than BE. Still pH remains more robust measure and according to last study of Georgieva et al. remains the most informative [45].

- Neonatology - complete neonatological reports were acquired for all the cases in pre-prepared database. No severe cases of neonatal morbidity were found, no hypoxic ischemic encephalopathy, no seizures (for details on neonatal morbidity see [55]).

- Subjective evaluation of the outcome of the delivery based on Apgar's score (Apgar), where five categories 
are used to assess the newborn child in $1^{s t}, 5^{\text {th }}$ and $10^{\text {th }}$ minute [56].

The complete database was used for inter-intra observer variability study. In this study 9 senior obstetricians evaluated CTG signals. The clinical evaluation will be added to the database as soon as processed.

\section{Signal criteria}

When the data were filtered according to the clinical information, we have applied the following criteria on CTG records:

- Signal length - we have decided to include 90 minutes preceding the delivery, where the delivery time represents also the time when the objective $(\mathrm{pH}$, etc.) evaluation of labor was acquired.

- I. stage - the length of the I. stage was limited to a maximum of 60 minutes in order to keep recordings easily comparable. The minimal length was dependent on the $\mathrm{pH}$ of the records in question - to include as much abnormal records as possible. Thus the minimal length of the I. stage of 30 minutes was required for recording with $\mathrm{pH} \leq 7.15$ and 40 minutes for others. The time distance from the end of the I.stage to birth was not allowed to be larger than 30 minutes.

- II. stage - based on our previous experience with analysis of the II. stage of labor (active pushing phase), we limited the II. stage to 30 minutes at maximum. This also limits the possibility of adverse events occurring in the II. stage, which could disconnect CTG recording in the I. stage with objective evaluation of the delivery.

Given the restriction above the signals are 30(40)-90 minutes long depending on a) the length of the II. stage and also b) available signal in the I. stage. No signal ends earlier than 30 minutes before delivery.

- Missing signal - amount of missing signal was, except for the II. stage, kept to possible minimum. Nevertheless the trade-off between having full signal and having recordings with abnormal outcomes had to be made. No more than $50 \%$ of signal was allowed to be missing in the I. stage.

- Noise and artifacts - these are a problem especially for the recordings acquired by the ultrasound probe. Certainly in some recordings maternal heart rate is intermittently present. But even though it can pose a challenge for user of the database it also reflects the clinical reality.
- Type of measurement device - the database is composed as a mixture of recordings acquired by ultrasound doppler probe, direct scalp measurement or combination of both - again reflecting the clinical reality at the obstetrics ward of UHB.

\section{Description of the Database}

Records for the CTU-UHB database were selected based on clinical and technical criteria described above. Table 3 provides overview of patient and labor outcome measure statistics and Table 4 presents main parameters regarding the CTG signals. The CTG signals were transformed from proprietary Philips format to open Physionet format [57], all data were anonymized at the hospital and de-identified (relative time) at the CTU side. An example of one CTG record is shown in Figure 2.

\section{CTG database - vaginal deliveries}

The main part of the CTG database consists of 506 intrapartum recordings delivered vaginally. It means the deliveries got always to the II. stage of labor (fully dilated cervix, periodical contractions), even though not all deliveries had active pushing period. Some were delivered operatively by means of forceps or vacuum extraction (VEX). The main outcome measures are presented in Tables 3 and 4.

Please note the column "Comment", which gives additional information either with regard to the number of potential outliers or points out interesting features of the

\section{Table 3 Patient and labor outcome statistics for the CTG-UHB cardiotocography database}

\begin{tabular}{|c|c|c|c|c|}
\hline \multicolumn{5}{|c|}{$\begin{array}{c}506 \text { - Vaginal (44 - operative); } 46 \text { - Caesarean Section } \\
\text { US = 412; DECG = 102; US-DECG = 35; N/A = } 3\end{array}$} \\
\hline & Mean (Median) & Min & Max & Comment \\
\hline $\begin{array}{l}\text { Maternal age } \\
\text { (years) }\end{array}$ & 29.8 & 18 & 46 & Over 36y: 40 \\
\hline Parity & $0.43(0)$ & 0 & 7 & \\
\hline Gravidity & $1.43(1)$ & 1 & 11 & \\
\hline $\begin{array}{l}\text { Gestational } \\
\text { age (weeks) }\end{array}$ & 40 & 37 & 43 & Over 42 weeks: 2 \\
\hline $\mathrm{pH}$ & 7.23 & 6.85 & 7.47 & \\
\hline $\mathrm{BE}$ & -6.36 & -26.8 & -0.2 & \\
\hline $\begin{array}{l}\text { BDecf } \\
(\mathrm{mmol} / \mathrm{l})\end{array}$ & 4.60 & -3.40 & & \\
\hline Apgar 1 min & $8.26(8)$ & 1 & 10 & $\mathrm{AS} 1<3: 18$ \\
\hline Apgar $5 \mathrm{~min}$ & $9.06(10)$ & 4 & 10 & AS5 $<7: 50$ \\
\hline $\begin{array}{l}\text { Neonate's } \\
\text { weight (g) }\end{array}$ & 3408 & 1970 & 4750 & SGA: 17; LGA: 44 \\
\hline $\begin{array}{l}\text { Neonate's } \\
\text { sex (F/M) }\end{array}$ & $259 /$ & & & \\
\hline
\end{tabular}

Abbreviations: AS1, AS5 - Apgar score at $1^{\text {st }}$ and $5^{\text {th }}$ minute respectively; SGA, LGA - fetus small, large for gestational age. 


\section{Table 4 CTG signal statistics for the CTG-UHB cardiotocography database}

\begin{tabular}{|c|c|c|c|c|}
\hline \multicolumn{5}{|c|}{$\begin{array}{c}506 \text { - Vaginal (44 - operative); } 46 \text { - Caesarean Section } \\
\text { US = 412; DECG = 102; US-DECG = 35; N/A = }\end{array}$} \\
\hline & Mean & Min & Max & Comment \\
\hline $\begin{array}{l}\text { Length of I. } \\
\text { stage (min) }\end{array}$ & 225 & 45 & 648 & \\
\hline $\begin{array}{l}\text { Length of II. } \\
\text { stage (min) }\end{array}$ & 11.87 & 0 & 30 & \\
\hline $\begin{array}{l}\text { Dist. SignalEnd } \\
\text { to Birth (min) }\end{array}$ & 2.70 & 0 & 29 & Over 10 min: 9 \\
\hline $\begin{array}{l}\text { Noisy data } \\
\text { W1 (\%) }\end{array}$ & 12.38 & 0 & 74 & \\
\hline $\begin{array}{l}\text { Missing data } \\
\text { W1 (\%) }\end{array}$ & 3.59 & 0 & 87 & \\
\hline $\begin{array}{l}\text { Overall } \\
\text { W1 (\%) }\end{array}$ & 15.98 & 0 & 89 & Over 50\%: 18 \\
\hline $\begin{array}{l}\text { Noisy data } \\
\text { W2 (\%) }\end{array}$ & 13.42 & 0 & 49 & \\
\hline $\begin{array}{l}\text { Missing data } \\
\text { W2 (\%) }\end{array}$ & 0 & 0 & 0 & \\
\hline $\begin{array}{l}\text { Overall } \\
\text { W2 (\%) }\end{array}$ & 13.14 & 0 & 49 & Over 25\%: 98 \\
\hline $\begin{array}{l}\text { Noisy data II. } \\
\text { stage (\%) }\end{array}$ & 22.62 & 0 & 91 & \\
\hline $\begin{array}{l}\text { Missing data II. } \\
\text { stage (\%) }\end{array}$ & 8.47 & 0 & 100 & \\
\hline $\begin{array}{l}\text { Overall II. } \\
\text { stage (\%) }\end{array}$ & 31.26 & 0 & 100 & Over 50\%: 97 \\
\hline
\end{tabular}

W1 - 30 minute-long window beginning 60 minutes before end of the first stage of labor, W2 - 30 minute-long window beginning 30 minutes before end of the first stage of labor.

database such as number of pathological cases based on certain parameters or quality of the recording in each window.

\section{CTG database - deliveries by Caesarean Section}

The database was selected to have the majority of intrapartum recordings with vaginal delivery. Nevertheless due to low number of cases with severely-abnormal outcomes, we have decided to add all recordings delivered by Cesarean Section (CS) with abnormal outcomes that conformed with the requirements mentioned above (16 CS records). Additional 30 CS recordings with normal outcome were randomly selected and added as a controlgroup. This control should enable the user of the database to evaluate CS recordings separately, if necessary. The details of the CS part of the database can be found in Tables 3 and 4 .

\section{Additional perspectives on the database}

In addition to the tables presented above four more tables are included in the Additional files section. Additional file 1: Table S5 and Additional file 2: Table S6 show the structure of the database with respect to umbilical cord artery $\mathrm{pH}$ values. The main reason for presentation of theses tables is to allow clear visibility of the features' values and their change with different $\mathrm{pH}$. We are well aware of the article of Yeh [58], which states that there is weak relation between umbilical artery $\mathrm{pH}$ after delivery and negative outcome to the baby. Nevertheless the $\mathrm{pH}$ still remains the main "objective" parameter - a summary of the delivery - as clearly presented in [45]. Finally, two short Tables S7 and S8 in the Additional file 3 describe different risk factors presented in the database again related to umbilical cord artery $\mathrm{pH}$ on vaginal and CS part of the database, respectively.

\section{Utility and discussion}

The CTU-UHB database is the first open-access database for research on intrapartum CTG signal processing and analysis. In the following paragraphs we will highlight the subjects, that could, if unobserved, lead to problems with use of the database.

The CTU-UHB users should be aware that there is a possible noise in the clinical data, since some information had to be mined from free text. Even though the whole data was carefully checked it is possible that some noise is present. However, this noise should not significantly disrupt any results obtained. Also we note that, due to the selection process, the database is biased from normal population (disproportional amount of low $\mathrm{pH}$ deliveries etc.) but this bias is evident in all other studies and, more importantly, if we would keep the database in the original form, the potential users would be forced to select the data themselves - resulting in different selection criteria and making, again, any comparison across studies infeasible.

From Table 2 it is evident that each study used different outcome measures, or their combinations. Again, this makes any comparison across studies infeasible. There are two main sources of evaluation: objective by e.g. umbilical artery $\mathrm{pH}$, which is prominent example, and subjective evaluation by experts according to their knowledge and/or guidelines used. For the clarity reasons we will focus on non-expert outcome measures, as those are discussed in another recently prepared paper of our research group (Spilka et al.: Analysis of CTG interpretation by expertobstetricians, submitted).

Exact relation of umbilical $\mathrm{pH}$ after delivery to CTG/FHR is so far not fully understood, time between the recording and actual delivery plays a crucial role, and it seems that $\mathrm{pH}$ is only weakly correlated to clinical annotation $[59,60]$. The best example is the timely CS due to suspect CTG - the CTG is suspect/pathological but the intervention prevented the baby to get into real asphyxia that would be reflected in the $\mathrm{pH}$ value. Yeh [58] claims that there is only weak relation between $\mathrm{pH}$ and actual outcome for the well-being of the baby. Following work 


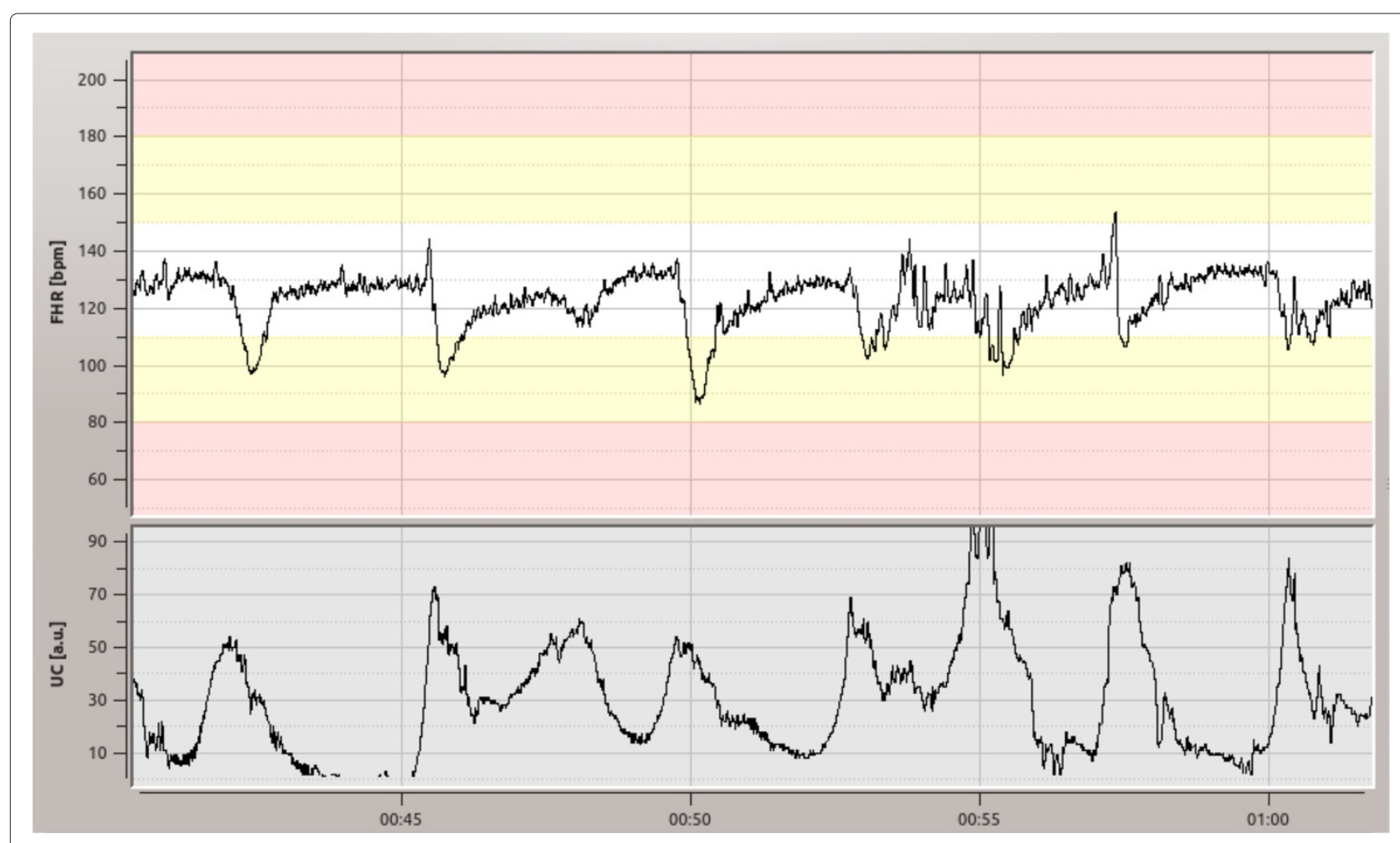

Figure 2 Record of fetal heart rate (FHR) and uterine contractions (UC). An example record from the database. Fetal Heart Rate at the top, and uterine contractions at the bottom. The end of I. stage of labor is marked with blue line and an arrow.

[45] on the same database relates low values of $\mathrm{pH}$ to higher risk of clinical complications. From the studies on cerebral palsy in neonates $\mathrm{pH}$ and BDecf are recommended as preferred measures [61] even though [62] says the opposite. Additionally intrapartum events and cerebral palsy are very rarely related by the intrapartum hypoxia only [63] and the real outcome of the delivery can be seen only in several years-long follow up [64].

There is no general agreement on the threshold, which should be used to distinguish between the normal and abnormal outcome of the delivery. There are several used/supported possibilities.

- Cerebral Palsy - $\mathrm{pH} \leq 7$ together with BDecf $\leq 12$ [65] was found to be related to significant increase of the cerebral palsy.

- Pathological - pH $\leq 7.05$ [16] is used as a threshold by most studies. Even though this value is not used unanimously, it is generally accepted as the threshold between pathological and not-pathological delivery outcomes. Combination with BDecf was used e.g. in [66].

- Abnormal (lower than normal) $\mathrm{pH}<7.10$ [67,68] this value is supported by recent works on the large Oxford database as well as used heuristically at the UHB as a sign of severe problems with the delivery.

- Abnormal (lower than normal) $\mathrm{pH}<7.15[69,70]$.
- Abnormal (lower than normal) $\mathrm{pH}<7.20$ [71] this particular value is also mentioned as an threshold to abnormal outcome $\mathrm{pH}$ by Irelands' obstetrician guidelines.

Regarding the Base deficit/base excess values the BDefc established by [72] is the only usable measure for assessment of metabolic hypoxia [53]. Nevertheless in many papers as well as in the clinical practice the base excess (BE) is used erroneously [53].

In general $\mathrm{pH}$ is more robust but is affected more by respiratory asphyxia, BDecf is more about metabolic asphyxia. Regarding the reliability of the objective measurements they are in general much more reliable than any expert opinion. Nevertheless biochemical measures are very dependent on the measuring procedure $-\mathrm{pH}$ is in general considered to be more robust than the BDecf where it is necessary to use consideration about the $\mathrm{pCO}_{2}$ measurements [54].

Among undocumented parameters in the database, which could influence the shape and/or different properties of FHR one could count e.g. smoking [73], which can increase the heart rate, or epidural analgesia [74,75] responsible for intermittent fetal bradycardia due maternal intermittent hypotension. Some risk factors can influence the look of the FHR such as diabetes mellitus, where FHR looks more immature [76]. Also technical 
parameters can influence the FHR itself - such as size of autocorrelation window for deriving FHR from ultrasound [77], or the derived parameters - such as power spectral density (PSD) of FHR, which can be affected by the type of interpolation [78].

Length of the data used is usually limited by the availability of the data. Really long signals (spanning from the check-in to delivery) enable us to create individualized approach to each fetus with regard to its starting point [53]. We have much more information to analyze, which can be positive [79] or confusing based on the point of view [80]. Short signals such as e.g. $70 \mathrm{~min}$ long [81] enables us to try to find direct relation between the features measured and the outcome.

Another question is how to treat the II. stage of labor. Will the length of it confuse the extracted features? General opinion on the second stage is that it is different from the I. stage - in shape of the signal. It is also very often noisy and it differs even in the clinical treatment where obstetricians are much more lenient to apply operative delivery in case of unclear trace [82].

\section{Conclusion}

The CTU-UHB database is the first open-access database available for research on intrapartum CTG signal processing and analysis. It is available at the Physionet website. The database is reasonably large and allows researchers to develop algorithms/methods for CTG analysis and classification. Using CTU-UHB database - different approaches can be easily compared one with another in the objective fashion. Intuitively, the use of common database can stimulate the research in CTG signal processing and classification and move the community to the ultimate goal - an automatic analysis of CTG and its possible extension to a decision support system for clinicians.

\section{Availability and requirements}

The database is published at http://physionet.org/ physiobank/database/ctu-uhb-ctgdb/ as an open-access database on the website dedicated to research in cardiology, heart rate variability and related fields.

The database is free to use for non-commercial purposes given that any publication using the database refers to this paper.

\section{Endnotes}

${ }^{\text {a }}$ The only published attempt in this direction was found in [83], but it was discontinued since.

b Czech Technical University - University Hospital Brno.

${ }^{\mathrm{c}}$ UCI Cardiotocography Data Set includes only CTG features not the signals - for more details see [84].

\section{Additional files}

Additional file 1: Table S5. Main clinical parameters of the vaginal delivery part of the CTG database and its relation to $\mathrm{pH}$

Additional file 2: Table S6. Main clinical parameters of the CS part of the CTG database and its relation to $\mathrm{pH}$.

Additional file 3: Table S7 and Table S8. Clinical parameters (risk factors and means of measurement) - vaginal delivery part of the CTG database $\mathrm{pH}$ related. Presentation: $O$ stands for occipital and $B$ for breech. Table S8 Clinical parameters (risk factors and means of measurement) sectio caesarea delivery part of the CTG database - $\mathrm{pH}$ related. Presentation: O stands for occipital and B for breech.

\section{Abbreviations}

CTG: Cardiotocography; FHR: Fetal heart rate; FECG: Fetal electrocardiography; UC: Uterine contractions; US: Ultrasound; BE: Base excess; BDecf: Base deficit in extracellular fluid; PSD: Power spectral density.

\section{Competing interests}

The authors declare that they have no competing interests.

\section{Authors' contributions}

All authors of the manuscript made a substantial contributions to the design of the study, data collection and analysis, results interpretation, to the article revising and final approval, namely: VC, JS, PJ and LH have formed the main outline of the study and specified the methodology and designed the database. VC, JS, MB and MH have been involved in the acquisition, cleaning and preprocessing of the data. PJ and LH have reviewed and finally selected clinical features to be used for description of the data. $L L$ helped with methodology and paper organization. VC, JS, LL and PJ drafted the manuscript. All authors read and approved the final manuscript.

\section{Acknowledgements}

The presented work was partially supported by Ministry of Healthcare of the Czech Republic grant No.NT11124-6/2010, by MH CZ - DRO (FNBr, 65269705) and SGS grant of the CTU SGS13/203/OHK3/3T/13. We would like to thank Philips Healthcare for their software for extraction of the data from the $O B$ TraceVue system to readable format and Ms. Monika Jiráčková from S\&T for facilitating the contacts to Philips.

\section{Author details}

${ }^{1}$ Department of Cybernetics, Faculty of Electrical Engineering, Czech Technical University in Prague, Prague, Czech Republic. ${ }^{2}$ Obstetrics and Gynecology clinic, University Hospital, Brno, Czech Republic.

Received: 12 July 2013 Accepted: 6 December 2013

Published: 13 January 2014

References

1. Heintz E, Brodtkorb TH, Nelson N, Levin LA: The long-term cost-effectiveness of fetal monitoring during labour: a comparison of cardiotocography complemented with ST analysis versus cardiotocography alone. BJOG 2008, 115(13):1676-1687.

2. Strachan BK, van Wijngaarden WJ, Sahota D, Chang A, James DK: Cardiotocography only versus cardiotocography plus PR-interval analysis in intrapartum surveillance: a randomised, multicentre trial. FECG Study Group. Lancet 2000, 355(9202):456-459.

3. d'Aloja E, Müller M, Paribello F, Demontis R, Faa A: Neonatal asphyxia and forensic medicine. J Matern Fetal Neonatal Med 2009, 22(Suppl 3):54-56.

4. Alfirevic Z, Devane D, Gyte GML: Continuous cardiotocography (CTG) as a form of electronic fetal monitoring (EFM) for fetal assessment during labour. Cochrane Database Syst Rev 2006, 3(3):CD006066.

5. Melman S, Schoorel E, Dirksen C, Anneke Kwee LS, de Boer F, Jonkers M, Mallory D, Woiski BWM, Doornbos JP, Visser H, Anjoke JM, Huisjes MMP, Delemarre FM, Kuppens SM, Robert Aardenburg IMVD, Vrouenraets FP, Lim FT, Kleiverda G, van der Salm PC, de Boer K, Sikkema MJ, Nijhuis JG, Hermens RP, Scheepers HC: SIMPLE: Implementation of recommendations from international evidence-based guidelines on 
caesarean sections in the Netherlands. Protocol for a controlled before and after study. Implementation Sci 2013, 8:3.

6. Lotgering FK, Wallenburg HC, Schouten $\mathrm{HJ}$ : Interobserver and intraobserver variation in the assessment of antepartum cardiotocograms. Am J Obstet Gynecol 1982, 144(6):701-705

7. FIGO: Guidelines for the use of fetal monitoring. Int J Gynecol Obstet 1986, 25:159-167.

8. Bernardes J, Costa-Pereira A, de Campos DA, van Geijn HP, Pereira-Leite L: Evaluation of interobserver agreement of cardiotocograms. Int J Gynaecol Obstet 1997, 57:33-37.

9. Blix E, Sviggum O, Koss KS, Oian P: Inter-observer variation in assessment of $\mathbf{8 4 5}$ labour admission tests: comparison between midwives and obstetricians in the clinical setting and two experts. BJOG 2003, 110:1-5.

10. Blackwell SC, Grobman WA, Antoniewicz L, Hutchinson M, Gyamfi Bannerman $C$ : Interobserver and intraobserver reliability of the NICHD 3-Tier Fetal Heart Rate Interpretation System. Am J Obstet Gynecol 2011, 205(4):378 e1-378.e5.

11. de Campos DA, Ugwumadu A, Banfield P, Lynch $P$, Amin P, Horwell D, Costa A, Santos C, Bernardes J, Rosén K: A randomised clinical trial of intrapartum fetal monitoring with computer analysis and alerts versus previously available monitoring. BMC Pregnancy Childbirth 2010, 10:71.

12. Henderson Z, Ecker JL: Fetal scalp blood sampling - limited role in contemporary obstetric practice: part I. Lab Med 2003, 34(7):548-553.

13. Henderson Z, Ecker JL: Fetal scalp blood sampling - limited role in contemporary obstetric practice: part II. Lab Med 2003, 34(8):594-600.

14. Dildy GA, Clark SL, Loucks CA: Intrapartum fetal pulse oximetry: past, present, and future. Am J Obstet Gynecol 1996, 175:1-9.

15. Norén H, Blad S, Carlsson A, Flisberg A, Gustavsson A, Lilja H, Wennergren $\mathrm{M}$, Hagberg $\mathrm{H}$ : STAN in clinical practice-the outcome of $\mathbf{2}$ years of regular use in the city of Gothenburg. Am J Obstet Gynecol 2006, 195:7-15.

16. Amer-Wåhlin I, Maršál K: ST analysis of fetal electrocardiography in labor. Semin Fetal Neonatal Med 2011, 16:29-35.

17. Ojala K, Vääräsmäki M, Mäkikallio K, Valkama M, Tekay A: A comparison of intrapartum automated fetal electrocardiography and conventional cardiotocography-a randomised controlled study. BJOG 2006, 113(4):419-423.

18. Westerhuis M, Kwee A, van Ginkel AA, Drogtrop AP, Gyselaers WJA, Visser GHA: Limitations of ST analysis in clinical practice: three cases of intrapartum metabolic acidosis. BJOG 2007, 114(10):1194-1201.

19. de Campos DA, Sousa P, Costa A, Bernardes J: Omniview-SisPorto ${ }^{\circledR}$ 3.5 - A central fetal monitoring station with online alerts based on computerized cardiotocogram+ST event analysis. J Perinat Med 2008, 36(3):260-264

20. Guijarro-Berdiñas B, Alonso-Betanzos A: Empirical evaluation of a hybrid intelligent monitoring system using different measures of effectiveness. Artif Intell Med 2002, 24:71-96.

21. Neilson DR, Freeman RK, Mangan S: Signal ambiguity resulting in unexpected outcome with external fetal heart rate monitoring. Am J Obstet Gynecol 2008, 198(6):717-724. http://dx.doi.org/10.1016/j. ajog.2008.02.030. [Monica].

22. Chudáček V, Spilka J, Janků P, Koucký M, Lhotská L, Huptych M: Automatic evaluation of intrapartum fetal heart rate recordings: a comprehensive analysis of useful features. Physiol Meas 2011, 32:1347-1360.

23. Spilka J, Chudáček V, Koucký M, Lhotská L, Huptych M, Janků P, Georgoulas G, Stylios C: Using nonlinear features for fetal heart rate classification. Biomed Signal Process Control 2012, 7(4):350-357.

24. Dawes GS, Visser GH, Goodman JD, Redman CW: Numerical analysis of the human fetal heart rate: the quality of ultrasound records. Am J Obstet Gynecol 1981, 141:43-52.

25. Jezewski M, Czabański R, Wróbel J, Horoba K: Analysis of extracted cardiotocographic signal features to improve automated prediction of fetal outcome. Biocybern Biom Eng 2010, 30(4):29-47.

26. Czabanski $\mathrm{R}$, Jezewski J, Matonia A, Jezewski M: Computerized analysis of fetal heart rate signals as the predictor of neonatal acidemia. Expert Syst App/ 1184, 39(15):6-11860.
27. Ocak H: A medical decision support system based on support vector machines and the genetic algorithm for the evaluation of fetal well-being. J Med Syst 2013, 37(2):9913.

28. Nielsen PV, Stigsby B, Nickelsen C, Nim J: Computer assessment of the intrapartum cardiotocogram. Il. The value of compared with visual assessment. Acta Obstet Gynecol Scand 1988, 67(5):461-464.

29. Chung TK, Mohajer MP, Yang ZJ, Chang AM, Sahota DS: The prediction of fetal acidosis at birth by computerised analysis of intrapartum cardiotocography. Br J Obstet Gynaecol 1995, 102(6):454-460.

30. Keith RD, Beckley S, Garibaldi JM, Westgate JA, Ifeachor EC, Greene KR: A multicentre comparative study of 17 experts and an intelligent computer system for managing labour using the cardiotocogram. Br J Obstet Gynaecol 1995, 102(9):688-700.

31. Bernardes J, de Campos DA, Costa-Pereira A, Pereira-Leite L, Garrido A: Objective computerized fetal heart rate analysis. Int J Gynaecol Obstet 1998, 62(2):141-147

32. Maeda K, Utsu M, Makio A, Serizawa M, Noguchi Y, Hamada T, Mariko K, Matsumoto F: Neural network computer analysis of fetal heart rate. J Matern Fetal Investig 1998, 8(4):163-171.

33. Lee A, Ulbricht C, Dorffner G: Application of artificial neural networks for detection of abnormal fetal heart rate pattern: a comparison with conventional algorithms. J Obstet Gynecol 1999, 19(5):482-485.

34. Chung DY, Sim YB, Park KT, Yi SH, Shin JC, Kim SP: Spectral analysis of fetal heart rate variability as a predictor of intrapartum fetal distress. Int J Gynaecol Obstet 2001, 73(2):109-116.

35. Strachan BK, Sahota DS, van Wijngaarden WJ, James DK, Chang AM: Computerised analysis of the fetal heart rate and relation to acidaemia at delivery. BJOG 2001, 108(8):848-852.

36. Siira SM, Ojala TH, Vahlberg TJ, Jalonen JO, Välimäki IA, Rosén KG, Ekholm EM: Marked fetal acidosis and specific changes in power spectrum analysis of fetal heart rate variability recorded during the last hour of labour. BJOG 2005, 112(4):418-423.

37. Cao H, Lake DE, Ferguson JE 2nd, Chisholm CA, Griffin MP, Moorman JR: Toward quantitative fetal heart rate monitoring. IEEE Trans Biomed Eng 2006, 53:111-118.

38. Salamalekis E, Hintipas E, Salloum I, Vasios G, Loghis C, Vitoratos N, Chrelias C, Creatsas G: Computerized analysis of fetal heart rate variability using the matching pursuit technique as an indicator of fetal hypoxia during labor. J Matern Fetal Neonatal Med 2006, 19(3):165-169.

39. Georgoulas G, Stylios CD, Groumpos PP: Predicting the risk of metabolic acidosis for newborns based on fetal heart rate signal classification using support vector machines. IEEE Trans Biomed Eng 2006, 53(5):875-884

40. Gonçalves H, Rocha AP, de Campos DA, Bernardes J: Linear and nonlinear fetal heart rate analysis of normal and acidemic fetuses in the minutes preceding delivery. Med Biol Eng Comput 2006, 44(10):847-855.

41. Costa A, Ayres-de Campos D, Costa F, Santos C, Bernardes J: Prediction of neonatal acidemia by computer analysis of fetal heart rate and ST event signals. Am J Obstet Gynecol 2009, 201(5):464.e1-464.e6.

42. Elliott C, Warrick P, Graham E, Hamilton E: Graded classification of fetal heart rate tracings: association with neonatal metabolic acidosis and neurologic morbidity. Am J Obstet Gynecol 2010, 202(3):258.e1-258.e8.

43. Warrick $P$, Hamilton E, Precup D, Kearney R: Classification of normal and hypoxic fetuses from systems modeling of intrapartum cardiotocography. IEEE Trans Biom Eng 2010, 57(4):771-779.

44. Helgason H, Abry P, Goncalves P, Gharib C, Gaucherand P, Doret M: Adaptive multiscale complexity analysis of fetal heart rate. IEEE Trans Biomed Eng 2011, 58:2186-2193.

45. Georgieva A, Payne SJ, Moulden M, Redman CWG: Artificial neural networks applied to fetal monitoring in labour. Neural Comput Appl 2013, 22:85-93.

46. Czabański R, Jezewski J, Wróbel J, Sikora J, Jezewski M: Application of fuzzy inference systems for classification of fetal heart rate tracings in relation to neonatal outcome. Ginekol Pol 2013, 84:38-43.

47. Callaway LK, Lust K, McIntyre HD: Pregnancy outcomes in women of very advanced maternal age. Aust N Z J Obstet Gynaecol 2005, 45:12-16.

48. Berglund S, Grunewald C, Pettersson H, Cnattingius S: Risk factors for asphyxia associated with substandard care during labor. Acta Obstet Gynecol Scand 2010, 89:39-48. 
49. Park Ml, Hwang JH, Cha KJ, Park YS, Koh SK: Computerized analysis of fetal heart rate parameters by gestational age. Int J Gynaecol Obstet 2001, 74(2):157-164

50. Bernardes J, Gonçalves H, Ayres-De-Campos D, Rocha A: Sex differences in linear and complex fetal heart rate dynamics of normal and acidemic fetuses in the minutes preceding delivery. J Perinatal Med 2009, 37(2):168-176

51. Singh T, Sankaran S, Thilaganathan B, Bhide A: The prediction of intra-partum fetal compromise in prolonged pregnancy. J Obstet Gynaecol 2008, 28(8):779-782.

52. Badawi N, Kurinczuk JJ, Keogh JM, Alessandri LM, O'Sullivan F, Burton PR, Pemberton PJ, Stanley FJ: Intrapartum risk factors for newborn encephalopathy: the Western Australian case-control study. BMJ 1998, 317(7172):1554-1558.

53. Rosén KG, Blad S, Larsson D, Norén H, Outram N: Assessment of the fetal bioprofile during labor by fetal ECG analysis. Expert Rev Obstet Gynecol 2007, 2(5):609-620.

54. Kro GAB, Yli BM, Rasmussen S, Norén H, Amer-Wåhlin I, Saugstad OD, Stray-Pedersen $B$, Rosén KG: A new tool for the validation of umbilical cord acid-base data. BJOG 2010, 117(12):1544-1552.

55. Mclntyre S, Taitz D, Keogh J, Goldsmith S, Badawi N, Blair E: A systematic review of risk factors for cerebral palsy in children born at term in developed countries. Dev Med Child Neurol 2012, (in press).

56. Finster $M$, Wood $M$ : The Apgar score has survived the test of time. Anesthesiology 2005, 102(4):855-857

57. Goldberger AL, Amaral LA, Glass L, Hausdorff JM, Ivanov PC, Mark RG, Mietus JE, Moody GB, Peng CK, Stanley HE: PhysioBank, PhysioToolkit, and PhysioNet: components of a new research resource for complex physiologic signals. Circulation 2000, 101(23):E215-E220.

58. Yeh $P$, Emary $K$, Impey L: The relationship between umbilical cord arterial pH and serious adverse neonatal outcome: analysis of $\mathbf{5 1 , 5 1 9}$ consecutive validated samples. BJOG 2012, 119(7):824-831.

59. Valentin L, Ekman G, Isberg PE, Polberger S, Maršál K: Clinical evaluation of the fetus and neonate. Relation between intra-partum cardiotocography, Apgar score, cord blood acid-base status and neonatal morbidity. Arch Gynecol Obstet 1993, 253(2):103-115.

60. Schiermeier S, von Steinburg SP, Thieme A, Reinhard J, Daumer M, Scholz M, Hatzmann W, Schneider KTM: Sensitivity and specificity of intrapartum computerised FIGO criteria for cardiotocography and fetal scalp pH during labour: multicentre, observational study. $B J O G$ 2008, 115(12):1557-1563.

61. Pierrat $V$, Haouari N, Liska A, Thomas D, Subtil D, Truffert $P$, d'Etudes en Epidémiologie Périnatale G: Prevalence, causes, and outcome at 2 years of age of newborn encephalopathy: population based study. Arch Dis Child Fetal Neonatal Ed 2005, 90(3):F257-F261.

62. Low JA: The current crisis in obstetrics. J Obstet Gynaecol Can 2005, 27(11):1031-1037.

63. Schifrin BS: The CTG and the timing and mechanism of fetal neurological injuries. Best Pract Res Clin Obstet Gynaecol 2004, 18(3):437-456.

64. Ingemarsson I, Herbst A, Thorngren-Jerneck K: Long term outcome after umbilical artery acidaemia at term birth: influence of gender and duration of fetal heart rate abnormalities. Br J Obstet Gynaecol 1997, 104(10):1123-1127.

65. MacLennan A: A template for defining a causal relation between acute intrapartum events and cerebral palsy: international consensus statement. BMJ 1999, 319(7216):1054-1059.

66. Westerhuis M, Moons KGM, van Beek E, Bijvoet SM, Drogtrop AP, van Geijn HP, van Lith JMM, Mol BWJ, Nijhuis JG, Oei SG, Porath MM, Rijnders RJP, Schuitemaker NWE, van der Tweel I, Visser GHA, Willekes C, Kwee A: A randomised clinical trial on cardiotocography plus fetal blood sampling versus cardiotocography plus ST-analysis of the fetal electrocardiogram (STAN) for intrapartum monitoring. BMC Pregnancy Childbirth 2007, 7:13.

67. Ross MG: Labor and fetal heart rate decelerations: relation to fetal metabolic acidosis. Clin Obstet Gynecol 2011, 54:74-82

68. Fulcher B, Georgieva A, Redman C, Jones N: Highly comparative fetal heart rate analysis. In Engineering in Medicine and Biology Society (EMBC) 2012 Annual International Conference of the IEEE. 2012:3135-3138. http:// ieeexplore.ieee.org/xpl/articleDetails.jsp?tp=\&arnumber=6346629\& queryText\%3DHighly+comparative+fetal+heart+rate+analysis
69. Georgoulas G, Stylios C, Nokas G, Groumpos P: Classification of fetal heart rate during labour using hidden Markov models. In Neural Networks, 2004. Proceedings. 2004 IEEE International Joint Conference on Volume 3. 2004:2471-2475. http://ieeexplore.ieee.org/xpls/abs_all.jsp? arnumber $=1381017 \&$ tag $=$

70. Salamalekis E, Thomopoulos P, Giannaris D, Salloum I, Vasios G, Prentza A Koutsouris D: Computerised intrapartum diagnosis of fetal hypoxia based on fetal heart rate monitoring and fetal pulse oximetry recordings utilising wavelet analysis and neural networks. $B J O G$ 2002, 109(10):1137-1142

71. Maharaj D: Intrapartum fetal resuscitation: a review. Internet J Gyneco Obstet 2008, 9(2):4800-4808

72. Siggaard-Andersen $\mathrm{O}$, Huch R: The oxygen status of fetal blood. Acta Anaesthesiol Scand Supp/ 1995, 107:129-135.

73. Oncken C, Kranzler H, O'Malley P, Gendreau P, Campbell WA: The effect of cigarette smoking on fetal heart rate characteristics. Obstet Gynecol 2002, 99(5 Pt 1):751-755.

74. Hill JB, Alexander JM, Sharma SK, McIntire DD, Leveno KJ: A comparison of the effects of epidural and meperidine analgesia during labor on fetal heart rate. Obstet Gynecol 2003, 102(2):333-337.

75. Cleary-Goldman J, Negron M, Scott J, Downing RA, Camann W, Simpson L, Flood P: Prophylactic ephedrine and combined spinal epidural: maternal blood pressure and fetal heart rate patterns. Obstet Gynecol 2005, 106(3):466-472

76. Tincello D, White S, Walkinshaw S: Computerised analysis of fetal heart rate recordings in maternal type I diabetes mellitus. BJOG 2001, 108(8):853-857.

77. Jezewski J, Roj D, Wrobel J, Horoba K: A novel technique for fetal heart rate estimation from Doppler ultrasound signal. Biomed Eng Online 2011, 10(92). http://dx.doi.org/10.1186/1475-925X-10-92

78. Cesarelli M, Romano M, Ruffo M, Bifulco P, Pasquariello G, Fratini A: PSD modifications of FHRV due to interpolation and CTG storage rate. Biomed Signal Process Control 2011, 6(3):225-230.

79. Graatsma EM, Jacod BC, van Egmond LAJ, Mulder EJH, Visser GHA: Fetal electrocardiography: feasibility of long-term fetal heart rate recordings. BJOG 2009, 116(2):334-337; discussion 337-338.

80. Sisco KM Cahill AG, Stamilio DM Macones GA: Is continuous monitoring the answer to incidentally observed fetal heart rate decelerations? J Matern Fetal Neonatal Med 2009, 22(5):405-409.

81. Schiermeier S, Hatzmann H, Reinhard J: The value of Dopple cardiotocogram computer analysis system $\mathbf{7 0}$ minutes before delivery. Z Geburtshilfe Neonatol 2008, 212(5):189-193.

82. Sheiner E, Hadar A, Hallak M, Katz M, Mazor M, Shoham-Vardi I: Clinical significance of fetal heart rate tracings during the second stage of labor. Obstet Gynecol 2001, 97(5 Pt 1):747-752.

83. Costa Santos C, Ayres de Campos D, da Costa Pereira A, Bernardes J: An interactive web site for research on fetal heart rate monitoring. Obstet Gynecol 2000, 95(2):309-311.

84. Bache K, Lichman M: UCI Machine Learning Repository. UCI Machine Learning Repository University of California, Irvine, School of Information and Computer Sciences 23 Dec. 2013. http://archive.ics.uci.edu/ml/ datasets/Cardiotocography

doi:10.1186/1471-2393-14-16

Cite this article as: Chudáček et al.: Open access intrapartum CTG database. BMC Pregnancy and Childbirth 2014 14:16. 